\title{
What drives sustainable luxury consumption in a status driven society like India?
}

\begin{abstract}
Luxury has become synonymous with status in countries like India. Where most of the consumers have been indulging in conspicuous consumption of luxury products. But are there consumers willing to spend on sustainable luxury in India? And what are their motivations to indulge in such a purchase? Consumers perceive sustainability as a complementary model to luxury, especially the wealthy Cervellon. ${ }^{1}$ However, little research has been done to identify what kind of consumers and motivations lead to sustainable luxury products purchase in India? Previous research shows that some consumers buy sustainable luxury as a means to show-off to others (Griskevicius, Tybur and Van den Bergh 2010). But could it be true for Indian consumers too? This paper includes empirical data from a survey that would reveal the underlying paradigms of sustainable luxury consumption in India. Understanding Indian consumer's preferences of sustainable luxury products can be useful for companies to plan their strategies accordingly. This research suggests implications for both academicians and managers interested in understanding the sustainable consumption pattern in India.
\end{abstract}

Keywords: sustainable luxury, indian luxury market, consumer behaviour, status consumption
Volume 2 Issue 4 - 2017

\author{
Mukta Ramchandani,' Julia van Holt, ${ }^{2}$ Coste- \\ Manière $\operatorname{Ivan}^{3}$ \\ 'PhD Candidate, Neoma Business School, France \\ ${ }^{2}$ Fashion and Sales-Management, International School of \\ Management, Germany \\ ${ }^{3}$ Luxury and Fashion Management, SKEMA Business School, \\ France
}

Correspondence: Coste-Manière Ivan, Luxury and Fashion Management SKEMA Business School, Sophia Antipolis,

France, Luxury and Fashion Management SKEMA Business School, Suzhou, China, Global Luxury Management SKEMA Business School, Raleigh, USA, Luxury Retail in LATAM, Florida International University, Miami, USA, Email ivan.costemaniere@skema.edu

Received: July 07, 2017 | Published: August 09, 2017

\section{Introduction}

Research in sustainable consumer behaviour is an important area with notable contributions in the field from various researchers Barr ${ }^{2}$ Thøgersen. ${ }^{3}$ Sustainable consumption can be applied to many product and services sectors. Primarily focusing on sustainable behaviour of consumers from buying sustainable products which aim to preserve the environment or reduce the wastage of resources. Interestingly, in the luxury industry the big quest has been about understanding if sustainability and luxury can co-exist and how sustainability can be defined in the realms of luxury? It has been accepted in many journals and books that sustainability and luxury in fact go together Lochard \& Murat ${ }^{4}$ how long-term sustainability exists in the field of luxury ${ }^{5}$ and the emphasis of luxury is on timelessness, uniqueness, durable, less toxic and recycled materials Achabou \& Dekhili. ${ }^{6}$

Consumers think of a brand as an image Esch $^{7}$ of a particular company. Some brands are viewed as cheap and in expensive, while others are viewed as a better quality and expensive Kapferer. ${ }^{8}$ In their research, Cervellon \& Shammas ${ }^{1}$ show that luxury brands these days are complimentary with sustainability through ethos (e.g., eco-brands such as Stella McCartney (Kering/PPR) or Edun (LVMH) in luxury fashion or Tesla Roadsters and Venturi luxury cars), commitment all along the supply chain (Gucci group, LVMH, Porsche) and/or introduction of eco-collection and eco-lines (BMWi3 electric cars, Vranken-Pommery Pop Earth Champagne, Issey Miyake 132.5 origami design collection, Gucci sunglasses made out of liquid wood produced from sustainably managed forests).

\section{Consumer behaviour and sustainability}

Moving beyond the primary exploration in this field from products to consumers. Some researchers have explored what kind of consumers buy sustainable luxury products/services, why and under what circumstances?

In consumer behaviour most factors rely upon the following Stern: ${ }^{9}$
a. Motivations, attitudes and values
b. contextual or situational factors
c. social influences
d. personal capabilities and
e. habits

The topic of sustainable luxury consumption also lacks an in depth study from a growing country like India. A nation with a huge market share in luxury sector has to be studied for their perceptions about sustainability. A quest to be answered lies in the fact that majority of the luxury consumers in India are status oriented. Thus, can we say that status determine the perception of using sustainable luxury products? Or is it the need of being unique amongst the peers? What might make people consider a sustainable luxury product and what inferences for consumption can be drawn from it?

This paper studies the Indian consumer's perception and preferences for recycled luxury product. We tested this through a survey measuring people's response to luxury sunglasses made from recycled wood vs non-recycled wood. We chose sunglasses because it is a gender neutral product and is marketed in India as a unisex product.

\section{Derivatives of sustainable behaviour}

Costly signals: Costly signaling theory explains that Miller, ${ }^{10}$ Zaha$\mathrm{vi}^{11}$ both animals and humans often engage in altruistic acts, acts that seem to involve a sacrifice and primarily to convey or communicate a signal about themselves. ${ }^{12}$ For example, individuals often enact some altruistic behaviour to show they are elevated in status, called competitive altruism.

Need for status: Scholars have defined an individual's susceptibility to interpersonal influence as "the need to identify with, or enhance one's image in the opinion of significant others through the acquisi- 
tion and use of products and brands, and the willingness to conform to the expectations of others regarding purchase decisions". ${ }^{13}$ Studies have found that status seeking consumers are concerned with their peers and use brands to convey status ${ }^{14}$ Griskevicius discussed how people indulge in sustainable luxury just for the sake of status, a desire for status can spur self-sacrifice and present a powerful tool for motivating prosocial and proenvironmental action

Need for uniqueness: The theory of consumers' need for uniqueness explains how an individual's need for uniqueness can influence brand responses and the need to be different from others Ryan ${ }^{15,16}$ through the pursuit of material goods Knight $\&$ Kim. ${ }^{17}$

Anthropocentricism: Values are preceded by culture, society and personality, and have behaviour as its outcome Rokeach..$^{18}$ Anthropocentric people show environmental concern due to the reason that they think human comfort, quality of life and health can be dependent on the preservation of the environment Gagnon Thompson \& Barton. ${ }^{19}$ People are notoriously reluctant to change familiar patterns of behaviour, and making a switch to green behaviours often necessitates making sacrifices (e.g., paying more for a less effective product).

\section{Methodology}

Previous research on sustainable luxury has mostly been studied under qualitative techniques like interviews, Zaltman Metaphor Elicitation Technique (ZMET) etc. But our research paper uses empirical data from quantitative survey designed specifically to understand the specificities of the Indian consumers.

Therefore, an online survey was conducted on Qualtrics to understand the perception of Indian consumers on sustainable luxury products. The participants were asked to imagine that they are going for shopping sunglasses and if given a choice which out of the two options shown they would consider buying. Option A: Luxury Recycled Wooden Sunglasses, Option B: Luxury Wooden Sunglasses. After choosing, they had to explain their answer within an open question in Figure 1.

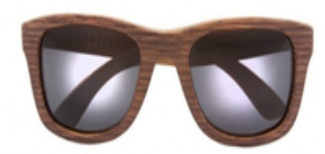

OPTION A : Luxury Sunglasses made from Recycled wood

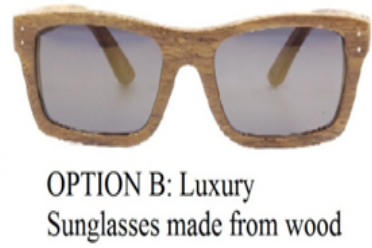

Figure I Option A, Luxury Recycled Wooden Sunglasses, Option B, Luxury Wooden Sunglasses.

In the next part of the survey, consumers where briefly asked about their perception of sustainability. Do they like it? Did they bought it before? Those questions were made as an overview of the customer's general view towards this survey. To dive deeper into their sense of luxury, the next block of questions discretely asked about their subconscious attitude towards luxury consumption. Luxury was referred to as 'feeling different', 'showing off' and 'spending money on not practical things'. Like this, it could be evaluated if the consumer likes to stand out through special goods or how much he likes having new and innovative products.

Afterwards, he was asked about his will to help his environment. These last four questions had the aim to analyse the consumers will to see more than him. The last question was very important, asking whether the consumer thinks that recycled luxury products might be a waste of money. This gives an idea not only about their answers to the first questions, but also about their whole sustainable consumption.

To guarantee a better evaluation process, the last part of the survey asked about the answerers demographics. Gender, age, income and the region he or she comes from, are all parameters that could influence the answers.

\section{Measurements}

The survey measured-an open question on the reason of the product choice. Questions on a Likert scale from 1(totally disagree) to 7 (totally agree) measured- Do you like recycled luxury products; Have you purchased recycled luxury products before, How much do you learn about luxury from your friends or family; Likeness of recycled luxury products; Purchasing experience of luxury product before; Need for status (3 items)- "I like to show off", "showing off makes me feel good", "I like to try new luxury products before anyone else does"; Need for uniqueness ( 2 items)-“feeling different in a crowd of people makes me feel good", I am attracted to new products"; Anthropocentricism (3 items) (adapted from Gagnon \& Barton 1994)-"I think small human actions can help preserve the planet, I like to help others, I like the idea of buying recycled luxury products"; and demographics questions like gender, age and place.

\section{Results and discussion}

118 participants (43 Males and 74 Females) participated in the online survey on Qualtrics conducted over a period of 4 days targeting only Indian consumers. Mean age: 29years, mean income- below 50 thousand Rupees per month. The analysis was done on SPSS for statistical findings. Following results were obtained:

\section{Product choice}

99 Participants chose Recycled Luxury Sunglasses option and 19 Participants chose non-recycled luxury sunglasses option. Most reasons cited for recycled luxury sunglasses were-environment friendly and more sustainable. Most reasons cited for choosing the non-recycled luxury sunglasses were-design and trust in Figure 2.

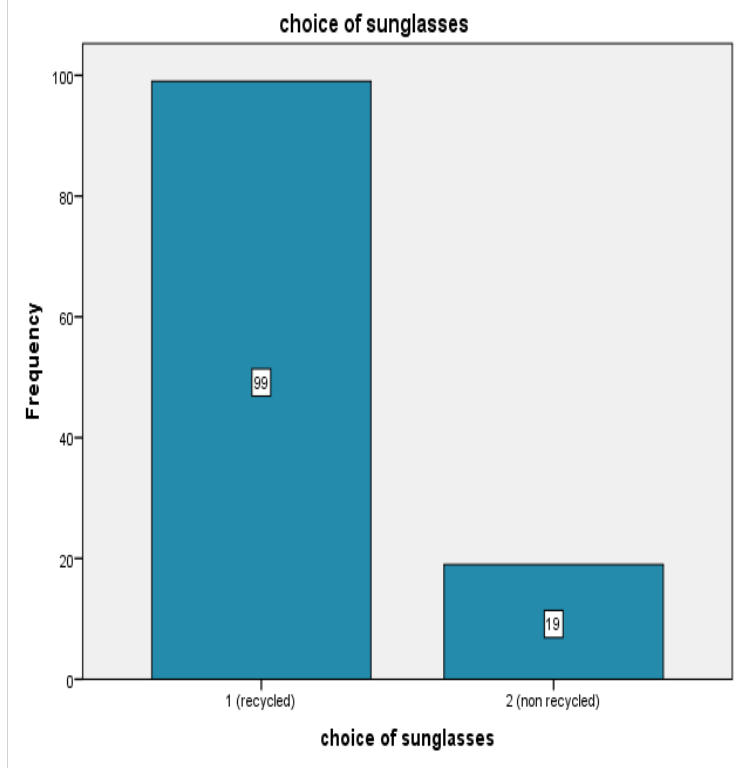

Figure 2 Recycled and non-recycled Luxury Sunglasses. 


\section{Need for uniqueness}

Average mean obtained was 3.38 showing lower need for uniqueness amongst the participants. The chi-square tests did not show any significant relationship for all the three items. That shows Indian consumers do not have the urge of conveying uniqueness through the choice of recycled or non-recycled luxury product.

\section{Need for status}

Average mean 4.84 showing that need for status was above average amongst the participants. A chi-square test reveals a significant relationship between choice of sunglasses and need for status (I like to show-off single item) $\chi^{2}(1, N=118)=14.347, \mathrm{p}<0.05$. People that chose recycled luxury sunglasses were found to be less status oriented. Therefore, for Indian consumers we can say that need for status does not determine the preference towards a sustainably luxury product.

Need for status $\propto \frac{1}{\text { Preference for sustainable luxury product }}$

\section{Anthropocentrism}

Average mean 5.57 showing that many participants were high in anthropocentricism (3 items combined). A chi-square test between choice of sunglasses and anthropocentrism reveals a significant relationship $\chi^{2}(1, \mathrm{~N}=118)=32.350, \mathrm{p}<0.01$. People that chose recycled luxury sunglasses showed higher anthropocentricism than people that chose non-recycled luxury sunglasses as shown in Table 1.

Table I means of status, uniqueness and anthropocentric

\begin{tabular}{llll}
\hline Statistics & Status & Uniqueness & Anthro \\
\hline NValid & 118 & 115 & 118 \\
Missing & 0 & 3 & 0 \\
Mean & 3.387 & 4.8478 & 5.5706 \\
Median & 3.3333 & 5 & 6 \\
Std. Deviation & 1.41419 & 1.58553 & 1.3595 \\
Percentiles 25 & 2.3333 & 4 & 4.6667 \\
50 & 3.3333 & 5 & 6 \\
75 & 4.3333 & 6 & 7 \\
\hline
\end{tabular}

\section{Likeness of recycled luxury products}

Chi-square test reveals a significant relationship between type of sunglasses chosen and likeness towards recycled luxury products $\chi^{2}(1,116)=34.34, p<0.001$. Participants that chose recycled luxury sunglasses option showed higher likeness towards recycled luxury products.

\section{Purchasing experience of luxury product before}

A chi-square test reveals a marginal significant relationship between type of sunglasses chosen and if the person has purchased a recycled luxury product before $\chi^{2}(1,118)=3.419, p=0.06$. People that chose recycled luxury sunglasses had not purchased a recycled product before, meaning that prior experience of purchasing recycled luxury product did not affect the product choice. Hence, we can interpret that the Indian consumers are risk takers and they will be willing to try a new recycled luxury product.

\section{Gender}

Chi-square tests revealed a significant relationship between gender and the type of sunglasses $\chi^{2}(1, N=117)=9.787, p=0.02$. Females were found to choose the recycled luxury sunglasses more than men. This can be due to the fact that majority of the participants were females or because in general females show more sustainable behaviour in Figure 3 .

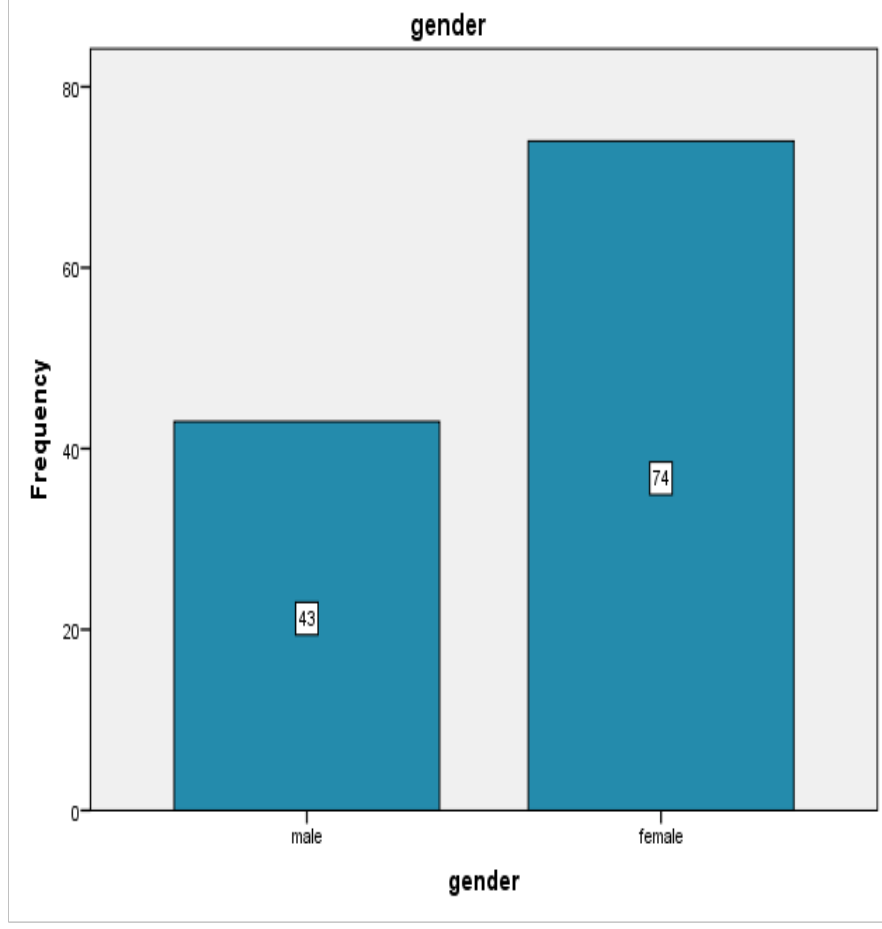

Figure 3 Gender.

\section{Conclusion}

The findings in our research show that Indian consumers are willing to accept sustainable luxury products. We found that when given a choice between sustainable and non-sustainable luxury product, majority of the people chose sustainable option. At least in the sector of recycled luxury sunglasses which we tested. Common barriers to sustainable product choice have been reluctance to try a new product and trust. Neither need for uniqueness nor need for status determines any significant relationship for the recycled product choices. But anthropocentric value was found to be a significant denominator in explaining the results. Females were found to prefer more recycled luxury sunglasses compared to men who shows that females could be a potential consumer for sustainable luxury brands more than men. Any luxury brand that wants to launch their sustainable luxury product in India would benefit from our research and understand certain specification of luxury consumers and what their perception is for sustainable luxury products. In addition, our research is useful for the research in the field of sustainable consumption and cross-cultural research for luxury goods and services.

\section{Future limitations}

Our study is a primary study in the field of sustainable luxury that explores motivations and perceptions of Indian consumers. However, further research needs to be done in order to find possible boundary 
conditions. Also, this study did not test real behaviours it tested product choices. For managerial implications we suggest that it could be a good idea to launch a sustainable luxury product in India. However, customer segmentation needs to be kept under consideration.

\section{Acknowledgements}

None.

\section{Conflict of interest}

Author declares that there is no conflict of interest.

\section{References}

1. Cervellon MC, Shammas L. The value of sustainable luxury in mature markets a customer-based approach. J Corporate Citizenship. 2013;52(12):90-101.

2. Barr S. Environment and society: Sustainability, policy and the citizen Burlington: Ashgate Publishing; 2008. p. 296.

3. Thøgersen J. How may consumer policy empower consumers for sustainable lifestyles? J Consumer Policy. 2005;28(2):143-178.

4. Lochard C, Murat A. Luxe et développement durable: La nouvelle alliance. Eyrolles, Paris, France; 2011. p. 288.

5. Coste-Manière I, Ramchandani M, Chhabra S, et al. Long-Term Sustainable Sustainability in Luxury. Where Else? In: Gardetti MA, Muthu SS, editors. Handbook of Sustainable Luxury Textiles and Fashion, Environmental Footprints and Eco-design of Products and Processes. Geramny: Springer Science; 2016. p. 17-34.

6. Achabou MA, Dekhili S. Luxury and sustainable development: Is there a match? J Business Research. 2013;66:1896-1903.

7. Esch FR. Strategie und Technik der Markenführung. Vahlen, Munich, Germany; 2010. p. 1-18.
8. Kapferer JN, Bastien V. The specifity of luxury management: turning marketing upside down. J Brand Management. 2009;16(5-6):311-322.

9. Stern P. Toward a Coherent Theory of Environmentally Significant Behaviour. J Social Issues. 2000;56(3):407-424.

10. Miller GF. The mating mind: How sexual choice shaped the evolution of human nature. Doubleday, New York, USA; 2000. p. 462.

11. Zahavi A. Mate selection: Selection for a handicap. J Theor Biol. 1975;53(1):205-214.

12. Gintis H, Bowles S, Boyd R, et al. Explaining altruistic behaviour in humans. In: Dunbar R, Barrett L, editors. Handbook of evolutionary psychology. Oxford University Press, England, UK ; 2007. p. 605-620.

13. Bearden WO, Netemeyer RG, Teel JE. Measurement of consumer susceptibility to interpersonal influence. J Consumer Research. 1989;15(4):473-481.

14. Ruvio A, Shoham A, Brencic MM. Consumers' need for uniqueness: short-form scale development and cross cultural validation. International Marketing Review. 2008;25(1):33-53.

15. Ryan HZ. Uniqueness and Innovativeness: A Look at Controversial Men's Fashion Products. Curtin Business School, Curtin University of Technology, Perth, Australia; 2008.

16. Tian KT, Bearden WO, Hunter GL. Consumers' need for uniqueness: Scale development and validation. $J$ Consumer Research. 2001;28(1):50-66

17. Knight DK, Kim EY. Japanese consumers' need for uniqueness: Effects on brand perceptions and purchase intention. J Fashion Marketing \& Management 2007;11(2):270-280.

18. Rokeach M. The Nature of Human Values. Political Science Quarterly. 1973;89(2):399-401.

19. Gagnon Thompson SC, Barton MA. Ecocentric and Anthropocentric Attitudes Toward The Environment. J Environmental Psychology. 1994;14(2):149-157. 